\title{
A Thermoelectric Generator Manufacture Research Based on Oscillating-Flow Heat Pipe Technology
}

\author{
Jieting Wei ${ }^{1}, \mathrm{Yu} \mathrm{Gu}{ }^{2}$, Yang $\mathrm{Liu}^{2}$ \\ ${ }^{1}$ Changchun Institute of Technology, Changchun,China \\ ${ }^{2}$ Northeast Dianli University, Jilin,China \\ Email:wjt8876@126.com
}

Received April, 2013

\begin{abstract}
Oscillating heat pipe is a new type of heat transfer. It not only has simple structure, non-pollution and low maintenance cost, but also has high heat transfer efficiency. Semiconductor thermoelectric generation technology is also an environmental technology. This article combines these two kinds of technology. By means of this generate electricity way, we make a set of system and the related experiment. Then we do some research on the feasibility of this system.
\end{abstract}

Keywords: Oscillating Heat Pipe; Thermoelectric Power Generation; Solar Energy

\section{Introduction}

Solar energy is a renewable green energy universal existed on earth. Its Application value is huge. If we make good use of it and convert light energy into electrical energy, we can replace the current fossil energy, because of its low pollution and waste.

Solar thermoelectric generation is a kind of green energy. The heat energy converts into electrical energy directly. Research on thermoelectric power generation was first started in the middle of the twentieth Century, with the problems of environmental pollution and oil and natural gas energy depletion of mainstream trend is becoming more and more serious, People began to study energy on this work, no noise, no exhaust waste, environmentally sound technology. The United States, the European Union, the developed country in the world attaches great importance to the study of thermoelectric power generation technology in civil field [1].

\section{Principle}

Solar thermoelectric generation is the use of the thermoelectric effect. The thermoelectric effect based on thermoelectric materials at both ends of the carrier motion, so as to realize the conversion of energy forms [2]. As shown in Figure 1, The $\mathrm{P}$ type and $\mathrm{N}$ type two different types of thermoelectric material is connected with the formation of PN junction. One side of this junction is in the condition of high temperature, the other side is at a low temperature state. PN type material high temperature side concentration is higher than the low temperature side. In the driving concentration gradient, electron dif- fusion spread to the low temperature side. Thus the formation of electromotive force has been made.

Capillary bend into oscillation flow heat pipe. It consists of the evaporation heating section, adiabatic section and condenser section. The heating section absorbs heat. The heat is transferred to the condensation section through the adiabatic section. Because of the tube vacuum, the refrigerant evaporation temperature is low, and vaporization speed is fast. When heating, because the heating period of absorption heat to make the tube steam column becomes larger. At the same time, there are new bubbles made. The bubble bigger push pipe steam column and liquid column flow. When the liquid and vapor column after condensation segment, heat is released and steam shrinks, because of the temperature of heating section and condensing section. The bubble expands in the heating section and shanks in the condensation side. Reciprocating flow formed in the cold end pressure

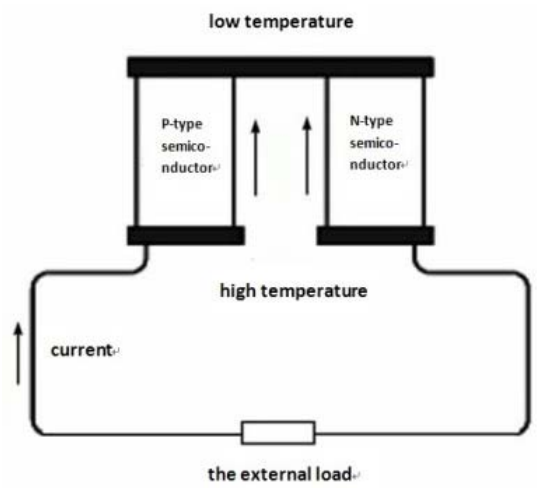

Figure 1. Principle of thermoelectric power generation. 
prompted the refrigerant in the tube. Because of the existence of the vacuum tube, vaporizing move fast, expansion resistance is very small, and the refrigerant flow speed is quick. The oscillatory flow heat pipe heat transfer effect is very good.

\section{System Structure}

Power generation device mainly comprises a solar collector tube system, oscillating heat pipe radiator, thermoelectric module, solar power controller, maintenance-free lead-acid battery and solar energy LED light Its composition is shown in Figure 2.

\subsection{Solar Vacuum Collector System}

The collector is composed of 5 diameter metal glass vacuum heat pipes $(\varphi 70 * 1900)$ parallel access collector aluminum block.

\subsection{Oscillating Heat Pipe Radiator}

The radiator adopts copper brass(Internal diameter $2 \mathrm{~mm}$, length $2.4 \mathrm{~m}$ ); The number of elbow is 16 . Filling material is ethanol; the filling rate is $60 \%$.

\subsection{Thermoelectric Modules}

Appearance size: $40 * 40 * 4 \mathrm{~mm}$; Maximum temperature: $200^{\circ}$; The maximum power voltage:7.62 V (temperature differential is $120^{\circ}$ ); Maximum short-circuit current: $1050 \mathrm{MA}$ (temperature differential is $120^{\circ}$ ); internal resistance: $4.8 \Omega$.

\subsection{Solar Power Controller}

Size: $133 \mathrm{~mm}$ x $70 \mathrm{~mm}$; Rated charging current: $5 \mathrm{~A}$; Direct charging voltage: $14.4 \mathrm{~V}$; the controller is sampled by computer chip on the battery voltage, discharge current, environment temperature. Through the calculation of the control module, we can better ensure the battery's work. Its working principle is shown in Figure 3.

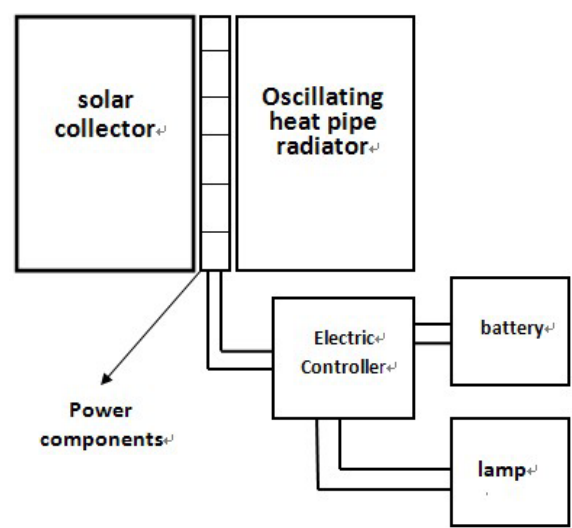

Figure 2. The structure of power generation device.

\subsection{Storage Battery and a LED Lamp}

Battery is a kind of $12 \mathrm{~V}$, and $4.5 \mathrm{Ah}$ maintenance-free lead- acid solar battery. The specification of the LED energy-saving light is $1.5 \mathrm{~W}$ and $12 \mathrm{~V}$.

\section{Experiment}

\subsection{Experimental Scheme}

Firstly, we test the performance of monolithic power components and Get the right data to plan experiment scheme. The test results are shown below in Figure 4 to Figure 6:

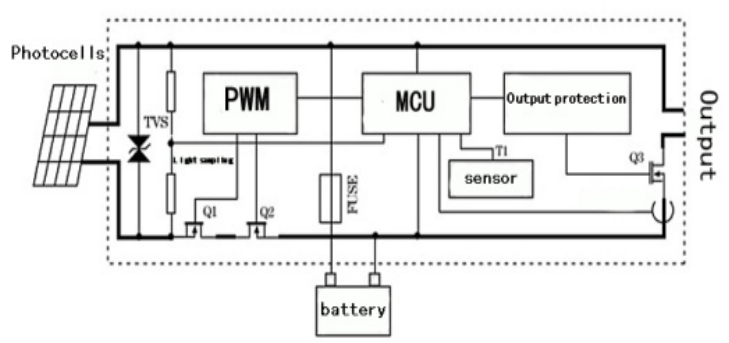

Figure 3. The principle of controller.

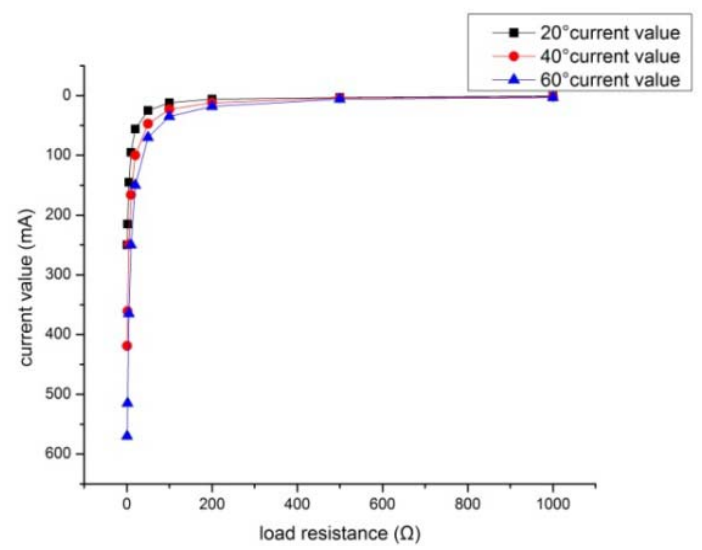

Figure 4. Current value among different temperatures.

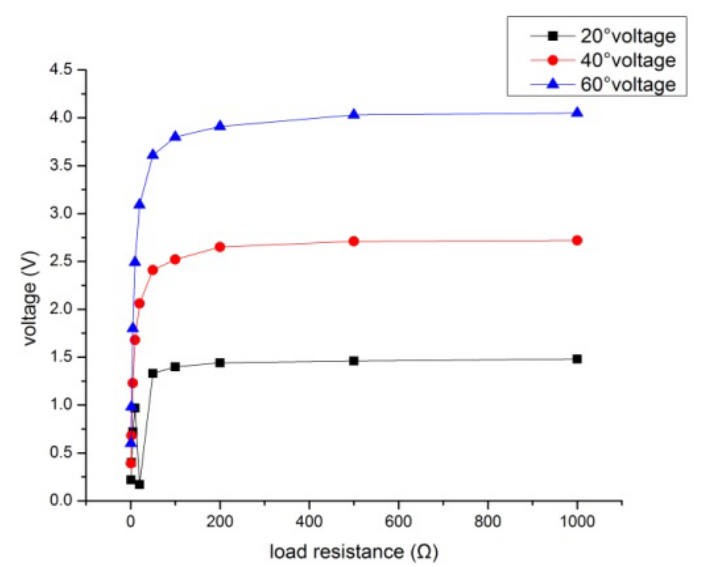

Figure 5. Voltage value among different temperatures. 


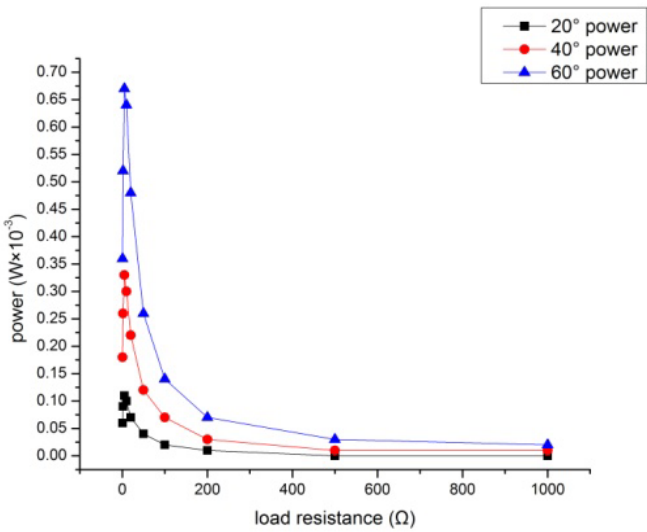

Figure 6. Power value among different temperatures.

We can find out from the experiment that the best matching resistor of single power components is 5-10 $\Omega$. At this time at a fixed temperature difference, the power of components is higher and the current is larger. Because of the small current in single power components [3], it is not suitable for charging. The experimental plan should adopt parallel and series combination. After many times of calculation and test, we decide that 4 generation components connected to a group. This is to ensure that the output current reaches the charging current. Then nine groups are in series. The purpose is to reach the charging voltage.

Then we select one day of representative spring in Changchun area to make the experiment. In the end, we get the relationship between voltages, current, temperature and radiation. Testing time is from 7:50 to the end of 17:50. Results are shown from Figure 7 to figure 10:

Figure 7 shows that solar radiation peaks throughout the whole day and noon time reaches the maximum value. This is shown in Figure 8, the temperature of aluminum block is the highest value in one day. The maximum value can reach $81^{\circ}$. Power generation equipment is in the best condition at the same time.

Figure 8 shows that When the temperature of the heat collecting aluminum block reached $79.7^{\circ}$, the temperature of Radiator has a gradient change. The temperature of bottom surface of Radiator has been greatly reduced.Then it has a oscillating variation. The radiator should be in the oscillating heat pipe effect status. The heat pipe cooling effect enhanced and Thermal resistance is reduced. Then the heat collecting aluminum block temperature ascension is also slow.

Figure 9 shows that the effect of oscillating heat pipe makes open circuit voltage larger and reach to $12.8 \mathrm{~V}$. Battery can be charged in this time. In Figure 8 we can know, in the experiment, the charging time is about one hour and a half.

Figure 10 shows that open circuit current value has been maintained at a relatively high value in the whole experiment. It is owing to the parallel to the power assembly. Because of Ohm law, Generating parallel can get a large amount of current.

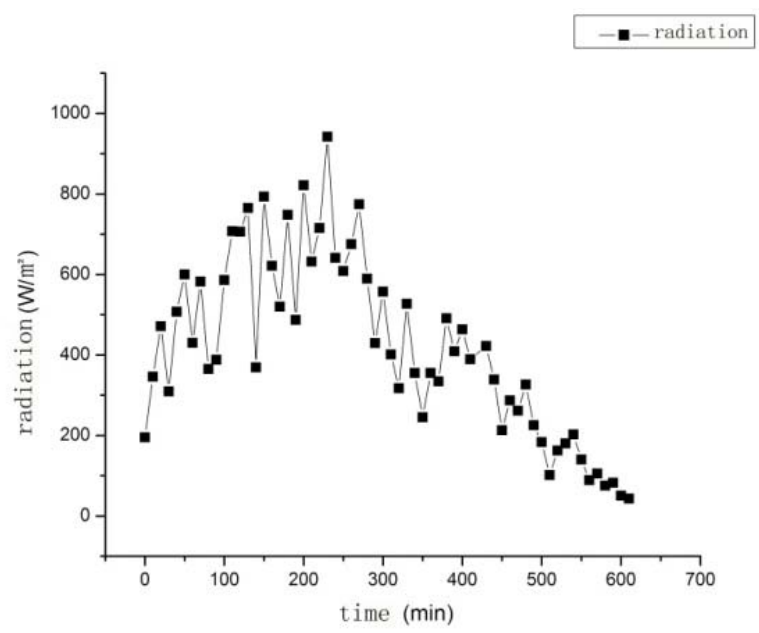

Figure 7. Radiation levels.

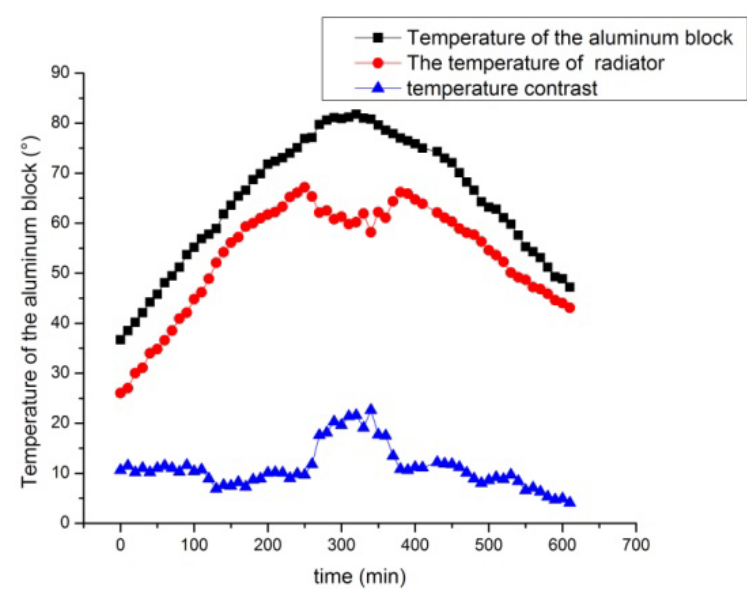

Figure 8. The temperature of aluminum block and the radiator surface.

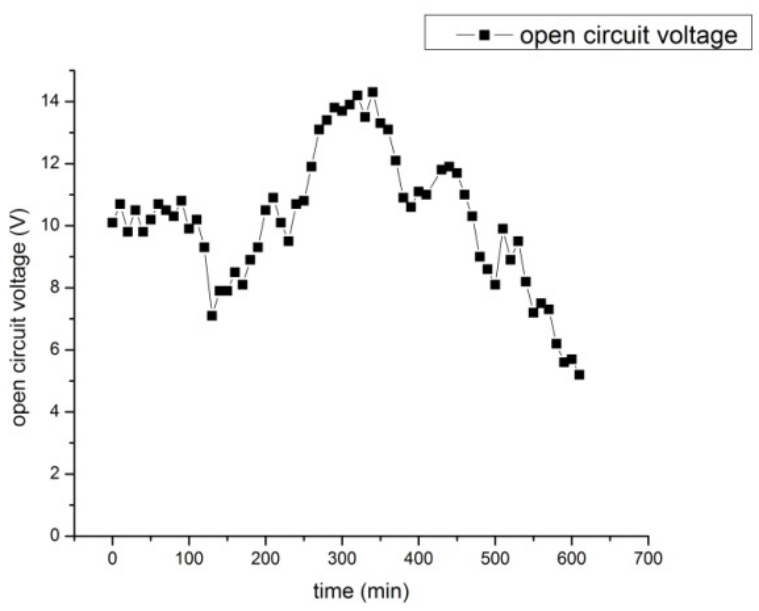

Figure 9. Relation between the voltage and time. 


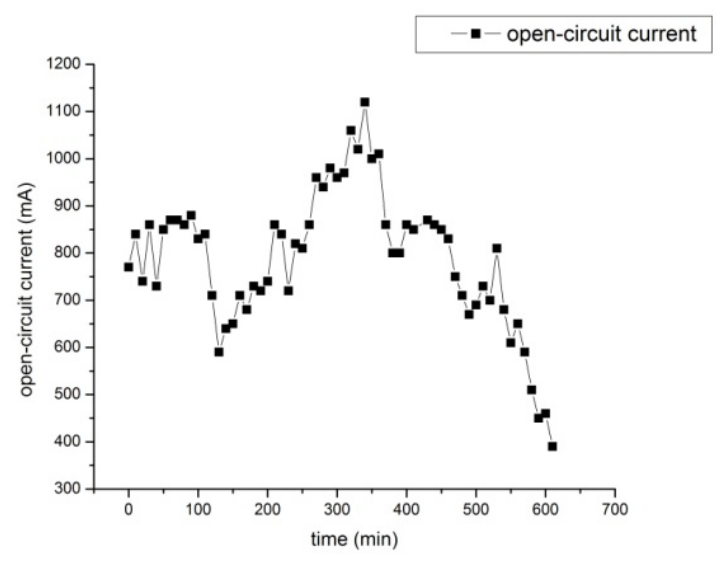

Figure 10. Relation between the current and the time.

After several days of testing, In the similar weather conditions, Charging battery for two to three days can make LED lamp lighting and a long time lighting.

\section{Feasibility Analysis}

In most areas in China, there are lots of solar energy resources. The average energy flow density of the solar energy(I) is more than $1000 \mathrm{~W} / \mathrm{m}^{2}$.In some western provinces, the highest value will reach $1750 \mathrm{~W} / \mathrm{m} 2$, the photothermal conversion efficiency value $(\eta)$ of High-quality solar collector is more than 0.75 . The total area of single tube sheet metal (s) is $0.25 \mathrm{~m}^{2}$. This device has five tubes, so total area of it(S) is $S=5 \times 0.25=1.25 \mathrm{~m}^{2}$. The average daily sunshine time(T) is $4 \mathrm{~h}$. The average of daily collected energy (E0) will be $\mathrm{E} 0=\mathrm{I}^{*} \mathrm{~T} * \mathrm{~S} * \eta$. If the percentage of the power $(\xi)$ absorbed in the collector is $60 \%$. The efficiency of power components can reach $10 \%$ and solar panel conversion rate was $95 \%$. The total amount of power:

$$
\mathrm{E}=\mathrm{E}_{0} * \xi * 0.1 * 0.95 \approx 7.7 \times 10^{5} \mathrm{~J} \approx 0.21 \mathrm{kWh}
$$

Assumed that the family lighting power $\mathrm{P}=150 \mathrm{~W}$, the device can generate electricity for 1.4 hours. If we improved lighting equipment, lingting time will be greatly extended.

\section{Summary}

The power system with no pollution, no noise, low maintenance cost of oscillating heat pipe radiator has high heat transfer efficiency. Therefore this device is in accordance with the national development of low carbon economy. This equipment is easy to transform and has ability to adapt to the environment. So it is worth to popularize. But the problems need to be solved are improving the radiation efficiency of the radiator and the power efficiency of power assembly.

\section{REFERENCES}

[1] J. J. Zhou and W. L. Zhang, "Current status and characteristics of thermoelectric material," Journal of Hebei Polytechnic University, 31, 2, 2009, pp.77-78.

[2] A. R. Ram and R. J. Solar, "thermoelectric generator for micropower applications," Electronic Materials, Vol. 39, No. 9, 2010, pp.1735-1740. doi:10.1007/s11664-010-1190-8

[3] Y. D. Deng, "Research on automobile exhaust thermoelectric device and thermoelectric module layout," Journal of Wuhan University of Technology, Vol. 32, No. 2, 2010, pp. 265-267. 